\title{
Endovascular treatment of a combined pseudoaneurysm and arteriovenous fistula of the subclavian artery caused by a gunshot wound to the chest
}

\author{
Fausto Y. Vinces, DO, and David C. Sperling, MD, Bronx, NY
}

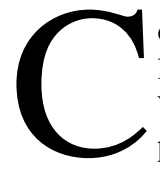

oncomitant pseudoaneurysms and arteriovenous fistulas of the subclavian artery are extremely uncommon. We present an endovascular repair of a combined pseudoaneurysm and arteriovenous fistula of the right subclavian artery caused by a gunshot wound to the clavicular region.

\section{Clinical Summary}

A 19-year-old man was brought to our regional level I trauma center with a single gunshot wound to the right infraclavicular area. Vital signs at admission included blood pressure of 148/70 $\mathrm{mm} \mathrm{Hg}$ in the right arm and 120/60 mm Hg in the left arm and a heart rate of 78 beats/min. A chest x-ray film demonstrated a bullet in the right shoulder area. The patient had palpable brachial, radial, and ulnar pulses. Because of the location of his injury, an emergency arch aortography with selective right subclavian angiography was performed. The study demonstrated rapid filling of the right subclavian vein during the arterial phase of the injection consistent with an extremely high-flow arteriovenous fistula between this vessel and the subclavian artery and a large outpouching of contrast that filled out the arterial phase and persisted on delayed imaging. This finding was consistent with a pseudoaneurysm of the right subclavian artery (Figure 1). It was decided to attempt an emergency endovascular treatment of the injury. A $6 \mathrm{~mm} \times$ $50 \mathrm{~mm}$ Viabahn covered stent (W. L. Gore \& Associates, Inc, Flagstaff, Ariz) was placed across the injured vessel. After placement of the stent, follow-up angiography demonstrated a successful exclusion of the pseudoaneurysm and arteriovenous fistula with a fully expanded stent graft (Figure 2).

Color Doppler scanning was performed before discharge and demonstrated a patent stent, with flow maintained along the venous and arterial segments of the covered stent. The patient was discharged with a full range of motion, and his outpatient follow-up has been uneventful.

\footnotetext{
From the Department of Surgery, Section of Trauma and Critical Care, ${ }^{\mathrm{a}}$ and the Department of Radiology, ${ }^{b}$ St Barnabas Hospital, Bronx, NY.

Received for publication Aug 7, 2004; revisions received Oct 28, 2004; accepted for publication Nov 4, 2004.

Address for reprints: Fausto Y. Vinces, DO, Department of Surgery, Section of Trauma and Critical Care, St Barnabas Hospital, 4422 Third Ave, Bronx, NY 10457 (E-mail: vincesf@optonline.net).

J Thorac Cardiovasc Surg 2005;130:225-7

$0022-5223 / \$ 30.00$

Copyright (C) 2005 by The American Association for Thoracic Surgery

doi:10.1016/j.jtcvs.2004.11.045
}

\section{Discussion}

Combined pseudoaneurysms and arteriovenous fistulas of the subclavian or axillary artery caused by trauma are extremely rare because these vessels are protected by the overlying bony and muscular structures. In most series penetrating trauma is the most frequent cause for these types of injuries, but blunt trauma is usually associated with major musculoskeletal and brachial plexus injury. ${ }^{1}$ Ischemia of the upper extremity is usually absent with injuries to these vessels because of the rich collateral circulation of the shoulder. In one series only $20 \%$ of patients had decreased or absent pulses. $^{2}$

Surgical management of these injuries usually requires a combination of a supraclavicular incision with clavicular resection or a median sternotomy with a supraclavicular extension. ${ }^{3}$ Kalakuntla and colleagues ${ }^{4}$ reported a postoperative complication rate of $24 \%$, and mortality ranges from $5 \%$ to $30 \%$ in various series.

There are several treatment options for pseudoaneurysms and arteriovenous fistulas. External ultrasound compression is mainly used for femoral artery pseudoaneurysms. ${ }^{5}$ Ultrasound-guided thrombin injection can be used for isolated pseudoaneurysms, but the presence of many side branches that communicate with the brain in this region precludes its use. ${ }^{6}$ Transcatheter coil embolization is also a treatment for excluding false aneurysms, but in our case this was not an option because the vessel involved was the main inflow line for the upper extremity and not a side branch.

The use of endovascular stent grafts reduces the acute need for surgical dissection and the risk for injuring the surrounding structures, such as the vagus nerve, recurrent laryngeal nerve, phrenic nerve, and innominate vein. ${ }^{7}$ In patients with trauma, careful selection of the patients on the basis of hemodynamic stability is extremely important.

A review of the largest series of this type of injuries demonstrated that there has not been a combined pseudoaneurysm and arteriovenous fistula of the subclavian artery caused by a gunshot wound treated with an endovascular stent graft. $^{8} \mathrm{Du}$ Toit and associates ${ }^{9}$ treated 4 combined lesions, but they were caused by stab wounds, and the procedure was not performed in the immediate acute setting. This patient underwent a successful placement of a covered stent in less than 1 hour after achievement of local anesthesia and sedation and was discharged within 5 days of admission.

In conclusion, this case report illustrates the use of endovascular techniques as an alternative approach to treatment of subclavian artery injuries in the hemodynamically stable patient with trauma. It is a cost-effective treatment that reduces patient discomfort, morbidity, blood loss, operative time, and the use of difficult maneuvers to expose the injured vessel. Finally, this new technique will require long-term follow-up and periodic graft assessment. 


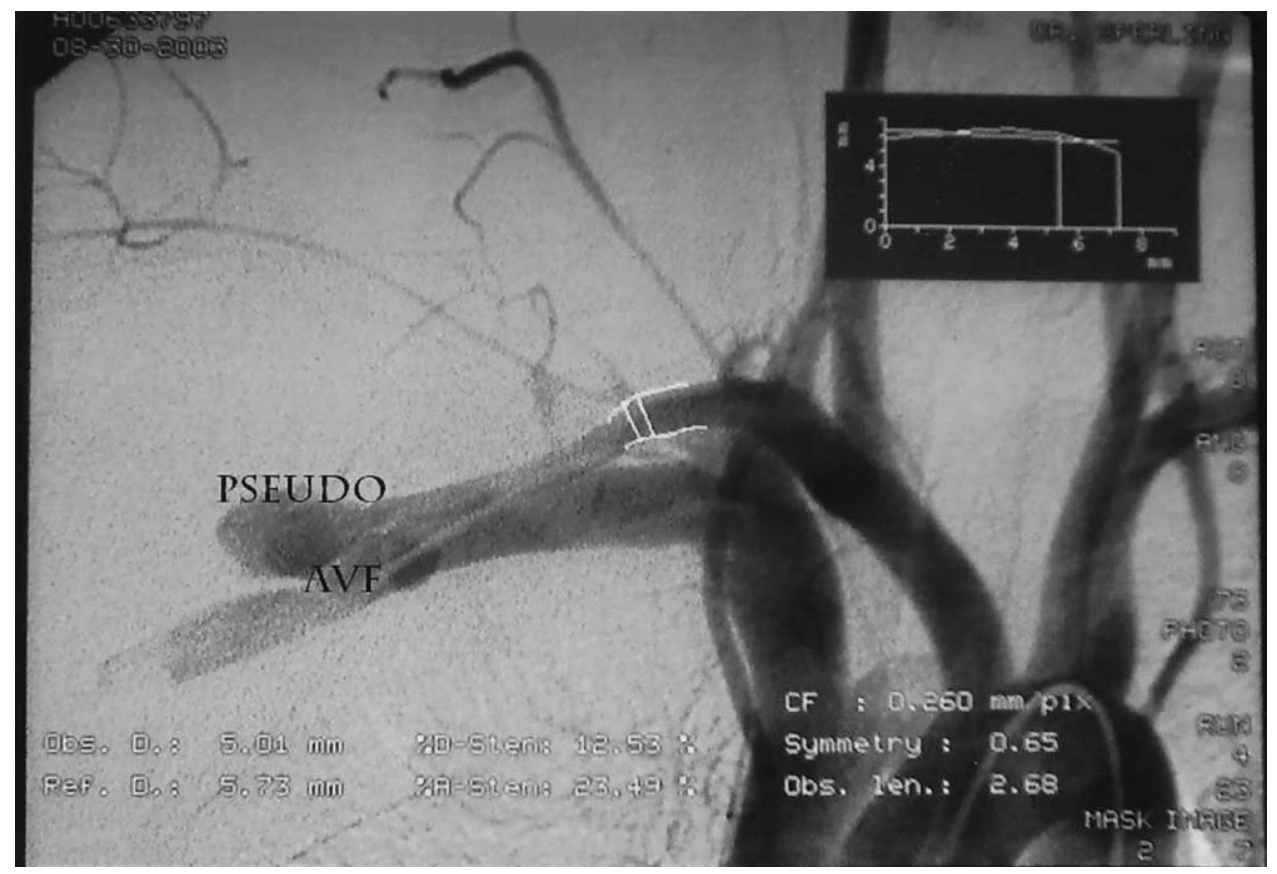

Figure 1. Right subclavian artery demonstrating a pseudoaneurysm (PSEUDO) and arteriovenous fistula (AVF).

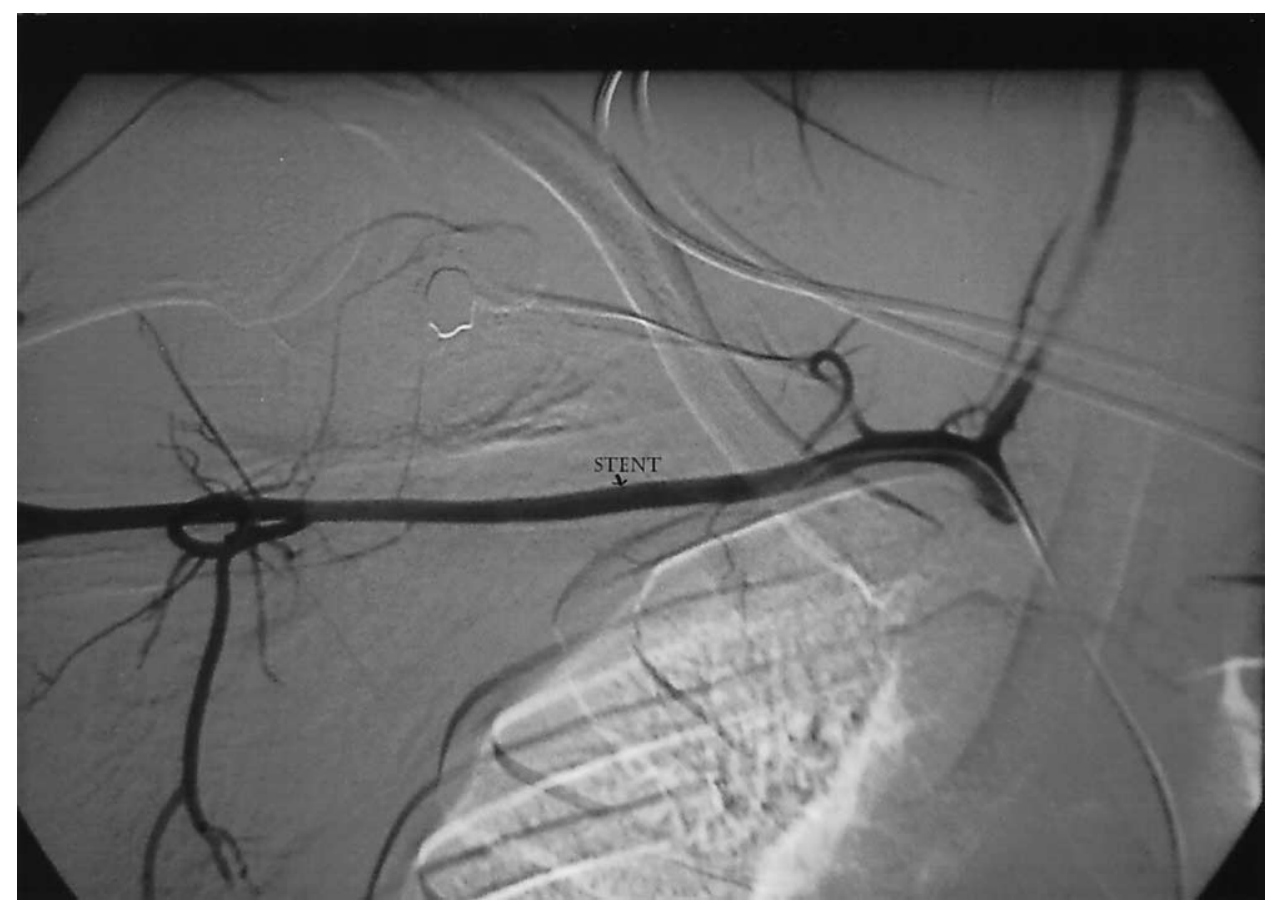

Figure 2. Subclavian artery after placement of an endovascular stent graft with resolution of pseudoaneurysm and arteriovenous fistula. 


\section{References}

1. Hoff SJ, Reilly MK, Merril WH, Stewart J, Frist WH, Morris JA. Analysis of blunt and penetrating injury of the in nominate and subclavian arteries. Am Surg. 1994;60:51-4.

2. Graham JM, Feliciano DV, Mattox KL, et al. Management of subclavian vascular injuries. J Trauma. 1980;20:537-40.

3. Stecco K, Meier A, Seiver A, Dake M, Zarins C. Endovascular stentgraft placement for treatment of traumatic penetrating subclavian artery injury. J Trauma. 2000;48:948-50.

4. Kalakuntla V, Vijaykumar P, Tagoe A, Weaver W. Six-year experience with management of subclavian Artery injuries. Am Surg. 2000;65:927-31.
5. Cope C, Zeit R. Coagulation of aneurysms by direct percutaneous thrombin injection. AJR Am J Roentgenol. 1986;147:383-7.

6. McConnel PI, Rehm J, Oltman DL, Lynch TG, Baxter BT. Thrombin injection for treating subclavian artery pseudoaneurysm. Surgery. 2000; 127:716-8.

7. Xenos ES, Freeman M, Stevens M, Cassada D, Pacanowski J, Goldman M. Covered stents for injuries of subclavian and axillary arteries. J Vasc Surg. 2003:38:451-4.

8. Demetriades D, Chahwan S, Gomez H, Peng R, Velmahos G, et al. Penetrating injuries to the subclavian and axillary vessels. $J$ Am Coll Surg. 1999;188:290-5.

9. Du Toit DF, Strauss DC, Blaszczyk M, De Villiers R, Warren BL. Endovascular treatment of penetrating of thoracic outlet arterial injuries. Eur J Vasc Endovascular Surg. 2000;19:489-95. 